\title{
Playful museum design: bringing the display to reality and bringing the reality to display
}

\author{
Rahmadean A. Purwatiani ${ }^{1}$, Tutin Aryanti ${ }^{1 *}$, and Restu Minggra ${ }^{1}$ \\ ${ }^{1}$ Universitas Pendidikan Indonesia, Department of Architectural Education, Jl. Dr. Setiabudi No. 207 Bandung, Indonesia 40154
}

\begin{abstract}
Lots of museums in Indonesia have very low visits. Considering their function as sources of knowledge to accommodate studies, education, and recreation purposes at the same time, museums should be fun and educating. This article aims to explore the concepts of a playful museum design to attract more visitors. The study employed qualitative approach using survey and case study. It proposes the use of the unusual and non-everyday building and spatial forms, the sequential flow, and scale arrangement to animate visitors' emotional tensions through flowing and dynamic circulations, bright and contrast colors, and spatial spontaneity. The museum brings in reality into display to allow visitors' hands-on experience and the display into reality to let visitors capture the feeling of what and how it took place in the real world. The playful design breaks museums' monotonicity.
\end{abstract}

\section{Introduction}

West Java (Indonesia) is a province rich with culture, including food. It has lots of traditional food, from which we can learn about the cultural values and local history. A number of scholars have studied the way food is culturally related to the local values. Van der Kroef, for example, explored the Indonesian rice legends and showed that rice, the major Javanese food, and its cultivation are probably as old as historic Javanese civilization. Rice has been intermingled with society's life and has become a legend as shown in the folklore on Dewi Sri, the widely-known goddess of rice [1].

Despite the centrality of food and its traditional cultivation in a society's cultural life, it is unfortunate that the modernized food processing and industries have endangered traditional food processing. A food museum is therefore an urgent solution to preserve Western Javanese food. This museum will provide information and education of food and its traditional cultivation in West Java. However, museums in Indonesia have been conventionally built as formal educational facilities appearing in banal and monotonous architecture. Museums have been the last object to visit and never a place for recreation.

As a public facility, a museum facilitates informal education [2]. In response to the contemporary needs, a museum should be design creatively [3]. It has to narrate a story to help visitors understand the exhibit [4].

This article aims to explore the design of the Food Museum of West Java, suing the theme "playful." The selection of the theme is based on the premise that a museum should be a place for education and recreation simultaneously. It should help both adults and children to feel the historic atmosphere when the displayed contents took place. The study used qualitative approached combining survey and case study.

\section{Playing and architecture}

\subsection{The challenges museums face}

The museum design multiple challenges. An expert on arts administration, Michael E. Shapiro, identifies that contemporary museums are challenged by at least three issues. First, they display old stuffs for the young generation. Second, museums have to embrace technology to attract audiences. Third, museums have to be able to earn its own living [5].

Allen identifies that there is a dilemma in the design of the public space: the exhibit has to accommodate learning but on the other hand, the design should also allow a diverse visiting public to make their own personal choices [6]. As a solution, a museum should be motivating every visitors' step. The design should encourage collaboration among visitors, incite both perceptual and intellectual curiosity, informative, allow the visitors to manipulate the objects or artefacts and the exhibits, incite imagination and give space for a sensory exploration [7].

\subsection{Human as a playing creature}

Playing is inherent in human being. Johan Huizinga argues for "homo ludens" or human as a playing creature [8]. He discusses the importance of the play as an inherent element of culture and society. Play is significant in the production of culture in a society. Further, Huizinga identifies that play has 5

\footnotetext{
* Corresponding author: tutin@upi.edu
} 
characteristics as follow: (1) play is free; (2) play is distinct from "ordinary" or "real" life; (3) play is separated from "ordinary" life, both in place and time; (4) play creates a specific order; and (5) play has no interest in materiality. It generates a sense of fun.

\subsection{Playful architecture}

Play is ever-present in human. Encouraging play and playfulness in the museum space, both for children and adults, will generate the sense of experience and fun, and thus make educating purpose is easier to be gained.

A number of architects have applied playfulness in their designs. The Greenwich Design District in London, for example, has been designed simultaneously by eight architects who built buildings that are contrast from its neighborhood [9]. This way, they bring the users to a different realm that is shifted from the ordinary surroundings.

Playful design allows the architect him-/herself to play. In their design of an integrated kindergarten and elementary school, Muthmainnah et.al. employed playing approach in arranging forms and spaces [10]. Using Lego and Uno-Stacko, the widely-known playing blocks, they utilized recycled containers as spatial modules for classrooms.

Tikhoniouk sees that playful space should be a place of enjoyment [11]. Creating playful space is inserting spontaneity or something that is out of the ordinary. The space should allow social interaction between neighbors and random strangers.

\section{The design of Western Javanese Food Museum}

We translate the theme "playful" into the design of the Western Javanese Food Museum as a solution to attract more visitors and audience. The main proposed concept is that the building should be out of its context and bring visitors to a realm that is different and separated from the ordinary reality.

\subsection{Playful site plan}

The site is arranged to accommodate: (1) Public zone containing a parking area and a plaza at the front and a food court and a souvenir shop at the east side; (2) Semipublic zone consisting of: lobby, ticketing, and information; administration areas, preservation and restoration rooms, and storage rooms; exhibition areas, auditorium, workshop, and library; (3) amphitheatres, open spaces, recreation area, rice fields, and garden.

The playfulness imbued in the site plan allows visitors to interact with each other in the provided open spaces while learning the Western Javanese traditional food. The area consists of rice fields, fruit and vegetable gardens, and a river, which originally exists on the site.

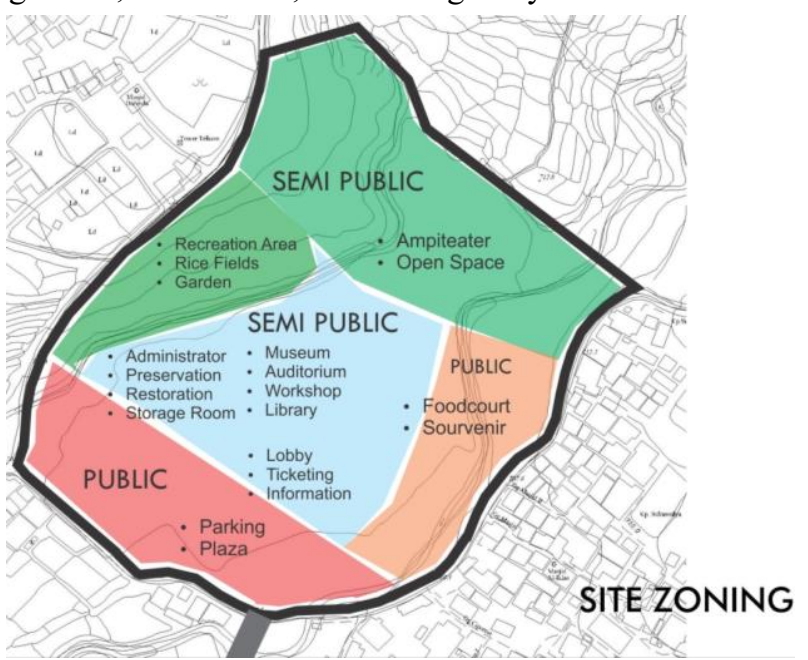

The site plan accommodates various activities such as planting rice, plowing fields cows, fruit picking, planting fruits and vegetables, and other educational recreations (Fig. 1).

Fig. 1. Site zoning.

\subsection{Playful building mass}

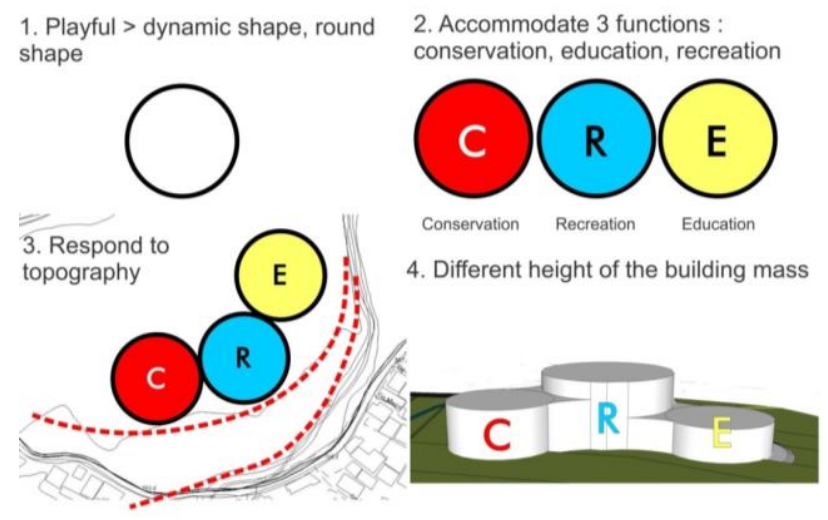

Fig. 2. Building mass transformation.

The building form is developed from a cylinder, which has a circle base plan. The circle is selected due to its dynamic, unmonotonous form that allows unlimited rotary and fold symmetries. The building is constructed of three parts, each of which is a cylinder that is duplicated. The three parts facilitate the three museum's main functions, i.e. conservation, education, and recreation. The three cylinders are arranged unsymmetrically and have different heights to respond the existing site, which topographically contoured, and to create a dynamic appearance (Fig. 2). 
The inner part of the cylinder is added with a void (Fig. 3), covered with a glass roof to allow natural lighting to penetrate into the three to four storied building.
Fig. 4. The colorful and dynamic building façade.

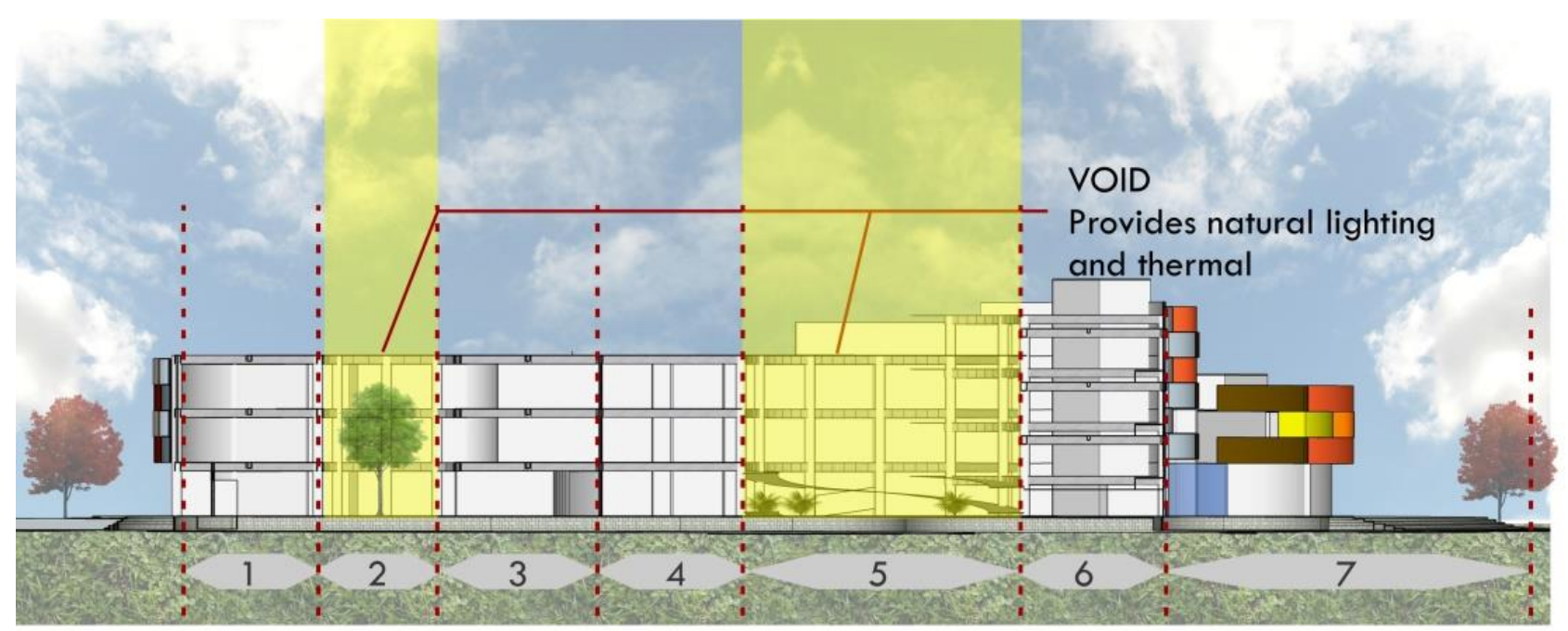

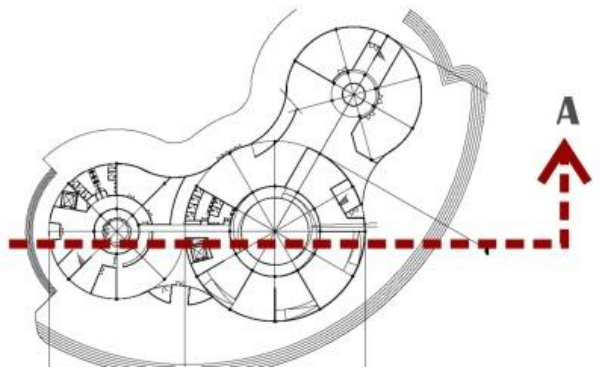

1. Administrator Area

2. Innercourt

3. Administrator Area

4. Exhibition Area
5. Innercourt + Display Area

6. Exhibition Area

7. Terrace

Fig. 3. The inner voids allow natural lighting.

\subsection{Playful façade}

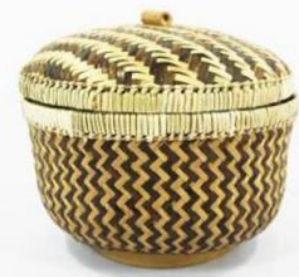

\section{Section A}

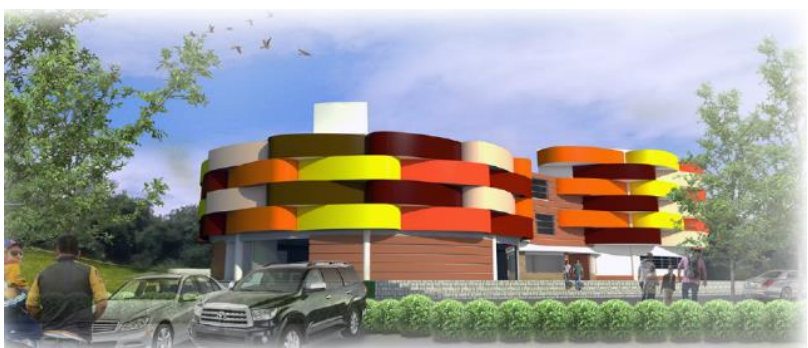

Fig. 4. The traditional Western Javanese rice basket.

The building façade is inspired by the traditional Western Javanese rice basket (Fig. 4). Made of woven bamboo, the façade allows ventilation across the building.

Playfulness is shown by the basket, which brings what is small-sized in the reality into an enlarged imitation of form as seen in the building mass. The woven bamboo is translated into the colorful double skin façade that catches the visitors' eyes once they approach the site. 


\subsection{Playful circulation}

Movement is critical in a museum design because it should create spatial meanings to visitors [2]. This building applies a radial circulation using continuous ramps. This allows visitors to enjoy the display without distracted by level split.

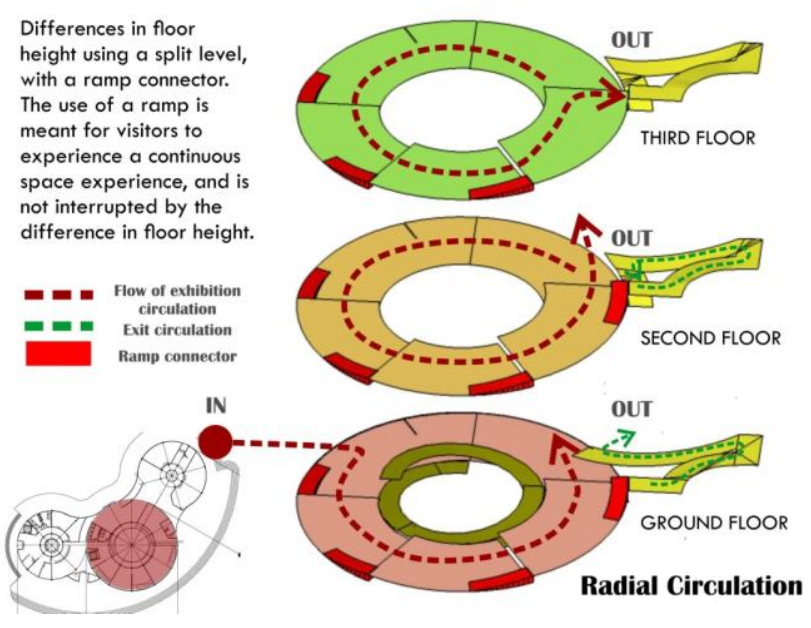

Fig. 5. Building circulation.

\subsection{Playful display}

The interior of the museum, particularly, that of the display areas, emphasizes the play of planes, texture, forms, and colors. The exhibits are displayed to expose the information, attract visitors' attention, and help them to comprehend the traditional food more easily.

There are seven display areas on the Western Javanese traditional food, including the history, culture, food processing ways and tools, specialty food, important people, and food achievements.

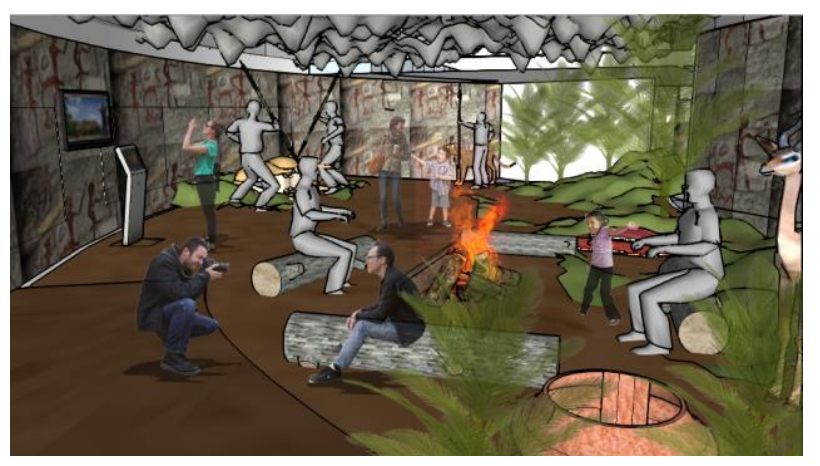

Fig. 6. The prehistoric era exhibits.

In the gallery of food history and culture (Fig. 6), for example, visitors are able to learn about eating culture from prehistoric era. There is no barrier between visitors and the exhibit so that they can touch and play with it, play a prehistoric human. This brings visitors to enter the prehistoric realm and understand what it felt to live in the era.

\section{Conclusion}

A playful-designed museum is a solution to make a museum a better place for education and recreation. The playfulness can be achieved through the forms, colors, spatial quality that are out-of-the-box, independent, and attractive yet following a certain order. It should offer spontaneity to allow excitement and experience and encourage social interaction.

The Western Javanese Food Museum is designed by exposing cylindric forms to allow a dynamic radial circulation inside the building, a playful and colorful façade to attract visitors' eyes, and inner voids to let natural light penetrates the interior, the use of flowing and fluid circulation, and interactive exhibits. Moreover, it is also provided with open spaces where social interaction can take place.

\section{References}

1. J. M. van der Kroef, Rice Legends of Indonesia, The Journal of American Folklore 65, 255, 49-55 (1952)

2. J. D. Wineman, J. Peponis, Constructing Spatial Meaning: Spatial Affordances in Museum Design, Environment and Behavior 42, 1, 86-109 (2010)

3. D. Flemming, Creative Space in S. MacLeod (ed.), Reshaping Museum Space: Architecture, Design, Exhibition 53-64 (New York, Routledge, 2005)

4. L. H. Skolnick, Towards a New Museum Architecture in S. MacLeod (ed.), Reshaping Museum Space: Architecture, Design, Exhibition 118-132 (New York, Routledge, 2005)

5. M. E. Shapiro, Eleven Museums, Eleven Directors: Conversations on Art and Leadership (Atlanta, High Museum of Art, 2016)

6. S. Allen, Designs for Learning: Studying Science Museum Exhibits that Do More than Entertain, Science Education 88, 1, 17-33 (2004)

7. D. L. Perry, What Makes Learning Fun?: Principles for the Design of Intrinsically Motivating Museum Exhibits (Lanham, Altamira Press, 2012)

8. J. Huizinga, Homo Ludens (Routledge, Switzerland, 1944)

9. E. Thorns, 8 Emerging Architects Create an Unexpected Playful Contrast for Greenwich's Design District, https://www.archdaily.com/880938/8-emergingarchitects-create-an-unexpected-playful-contrast-ingreenwichs-design-district

10. K. Muthmainnah, Designing using Lego and UnoStacko: A Playful Architecture for an Integrated Kindergarten and Elementary School, IOP Conference Series 180, 1 (2017)

11. E. Tikhoniouk, Playful Space, The RIAI Journal, http://architectureireland.ie/play-and-the-urbanrealm-playful-space 